Sorry, Not Sorry: Apologies and Denials in the \#MeToo Movement

Christopher P. Reinders Folmer*

Erasmus University Rotterdam

Note: to appear in In-Mind, http://www.in-mind.org/.

* Address correspondence to Chris Reinders Folmer, Erasmus School of Law, Erasmus University Rotterdam, Burgemeester Oudlaan 50, 3062 PA Rotterdam, the Netherlands, e-mail: reindersfolmer@essb.eur.nl.

Reinders Folmer is a postdoctoral researcher at the research program Behavioural Approaches to Contract and Tort at Erasmus School of Law, Erasmus University Rotterdam. 


\begin{abstract}
The \#MeToo-movement publically confronts alleged perpetrators of sexual misconduct with their transgressions. In return, the accused often struggle with the question of how to reply. What can research about trust and forgiveness teach us about the do's and don'ts of their responses?
\end{abstract}

Keywords: \#MeToo, trust, forgiveness, apology, denial 
Sorry, Not Sorry: Apologies and Denials in the \#MeToo Movement

The rise of social media has provided victims with new avenues for denouncing misconduct. Arguably the most remarkable example of this is the \#MeToo-movement, in which (alleged) victims of sexual misconduct publically accuse the (often wealthy, powerful, and/or famous) perpetrator via social media. Contrary to a court trial, the dispute is fought out in the open, under the gaze of millions, in the absence of tangible proof. These features mean that the \#MeToodiscussion is of profound interest to psychologists. One of the most interesting questions is how the accused respond. How do they reply to such allegations? And how effective is their response, both for victims and for spectators? In this contribution, we analyze some noteworthy examples, using the psychological literatures on trust $(1,2)$ and forgiveness (3).

\section{The psychology of trust}

When someone is accused of misconduct, our belief in such allegations is a question of trust. Do we consider the allegations to be credible, in light of the evidence, and our impression of the accused? Do we maintain our trust in them, in spite of the allegations? If we regard the accusation as credible, the matter becomes one of forgiveness: do we forgive the wrongdoer for their misconduct? And are we willing to reinstate our trust in them?

Psychologists regard trust as a state in which one is willing to be vulnerable based on positive expectations of another (2). Misconduct is a serious violation of those expectations. Accordingly, even allegations can strongly undermine our trust in the accused (4). This may have grave consequences, because untrustworthy individuals are likely to be ostracized by others (5). 
This is also apparent in the \#MeToo-discussion, where accusations have led to the exclusion of leading figures in business, entertainment, and politics.

It is crucial for the accused to respond in such a way that will enable them to retain the trust of others, or to regain it. There are several ways of doing so, including denial, reticence, and apology (1). Here, we zoom in on the most important responses in the \#MeToo-discussion: denial and apology. Below, we will learn why the accused choose these responses, and how these will impact the victim, the public, and the accused themselves. We illustrate this by means of some noteworthy \#MeToo-examples.

\section{Denial: Harvey Weinstein}

A first, common response to \#MeToo-accusations is to deny everything. An example of this is the statement of Hollywood film producer Harvey Weinstein, who was accused of sexual misconduct by more than 80 female actors. In his response, he strongly denied any sexual behavior without mutual consent. Allegations to the contrary were branded as distortions of the truth and slander.

By engaging in denial, the accused strives to regain the trust of others by claiming the allegations to be false (1). If the accused is successful in persuading their audience, the damage can immediately be undone: if there is no more reason to distrust the accused, their position is immediately restored. Denials are firstly offered by suspects who are falsely accused, and legitimately seek to clear their name. But denials are also used untruthfully by genuine wrongdoers, who seek to cast doubt on the accusations, and escape the consequences. This prospect is especially appealing for \#MeToo-suspects, because those consequences can be grave, and there is typically no firm proof against them. These reasons explain why denials are the 
default response to \#MeToo-accusations (e.g., singer Ryan Adams; Associate Justice of the Supreme Court of the United States Brett Kavanaugh) - even in cases where the suspect's guilt has subsequently been proven (e.g., actor Bill Cosby).

The effectiveness of denial is illustrated by an experiment by Kim and colleagues (4). Participants watched a videotaped job interview, in which a (fictitious) candidate was confronted with claims of fraud from a previous employer. The response of the candidate was manipulated: denying all accusations, or offering an apology. Participants indicated greater trust in the candidate if they denied than if they apologized. Therefore, denial can be an effective strategy to regain the trust of spectators - both for those who are truly innocent, and for those who seek to conceal their guilt.

How effective is Weinstein's denial? If there is no tangible evidence, a denial may be effective to restore one's public image. However, a denial does nothing to restore the harm that the victim has suffered, or to satisfy their need for affirmation and acknowledgement. Indeed, if the victim is convinced of the suspect's guilt, a denial will add insult to injury (1). This also highlights the risk of denial: should any evidence of guilt emerge later on, then trust in the accused will be decimated (4) - as in the case of former US President Bill Clinton. Similarly, Weinstein's denial has been met with disbelief - not because of firm evidence, but due to the number of accusers, and the similarities between their declarations.

\section{Apology: Kevin Spacey and Louis CK}

A far less common response to \#MeToo-accusations is to apologize. Examples of this are statements from actor Kevin Spacey and comedian Louis CK, after both were repeatedly accused of sexual misconduct. Nevertheless, if we tease them apart (as we will below), there are 
important differences between their responses - with important implications for their effectiveness.

In the social scientific literature, an apology entails that the wrongdoers admit fault and expresses remorse for their actions $(6,7)$. By doing so, they distance themselves from their actions, and thereby (implicitly) promise to not reoffend (1). In other words, an apology means more than just "I'm sorry". However, this distinction is less clear-cut in practice, such that the public may also experience more superficial accounts as an apology - as in the case of Spacey.

An apology serves victims by affirming their story, and by providing acknowledgement for their harm. Apologies may also benefit victims because they humiliate the wrongdoer, especially when in public (6). In these ways, apologies may help to reduce their sense of injury, and rebuild their self-esteem and status $(6,7)$. Moreover, the act of apologizing may create empathy for the wrongdoer, making it easier for others to forgive them (3).

According to Schumann (8), an apology should convey at least three key elements: remorse, admission of wrongdoing, and an offer to restore the harm. In addition, an apology may include sympathy for the victim, and the promise to not reoffend. In her research, however, Schumann observed that perpetrators often do not apologize so exhaustively (8). She asked participants to recall a situation in which they had offended or hurt someone, and to write down what they would say to the victim to end the dispute. The content of these responses was coded by the researchers. As it turned out, perpetrators tended to provide only a few of the apology elements, and especially lacked the three key elements.

The same pattern is apparent in Kevin Spacey's statement. Writing in response to accusations of sexual misconduct by fellow actor Anthony Rapp, he wrote: 
"I honestly do not remember the encounter, it would have been over 30 years ago. But if I did behave then as he describes, I owe him the sincerest apology for what would have been deeply inappropriate drunken behavior, and I am sorry for the feelings he describes having carried with him all these years."

"This story has encouraged me to address other things about my life. (...) in my life, I have had relationships with both men and women (...), and I choose now to live as a gay man. I want to deal with this honestly and openly and that starts with examining my own behavior." (Kevin Spacey)

How effective is this response? Spacey writes that he is sorry for the "feelings" that Rapp described, and acknowledges that it would have been "deeply inappropriate... behavior," "if [he] did really behave as [Rapp] describes." However, he does not indicate that he is sorry for the abuse, nor does he admit to being at fault. On the contrary, he "honestly does not remember the encounter," and even if it did occur, he was "drunk" (which would somehow make him less blameworthy). That he simultaneously comes out as gay only helps to distract further from the issue. According to Schumann's typology (8), Spacey therefore neglects to admit fault, nor does he offer to restore the harm. Rather, his response casts doubt over the accusation and his blameworthiness. It seems unlikely that this response will help Rapp to recover. Moreover, it seems unlikely that the public will be convinced of Spacey's innocence, if he himself seems to be unsure.

Why does Spacey offer such a limited apology? Why does he not plainly admit fault - in light of the importance of doing so for the victim, and for the forgiveness process? A first possibility: he is innocent, or believes himself to be. Perhaps he has experienced the incident differently than Rapp has, or maybe the accusation is altogether false. It may also be, however, that Spacey is in fact guilty, but does not want to admit so (6). As suggested by Schumann's 
research (8), wrongdoers often prefer to not accept responsibility. This firstly is due to the consequences: by doing so, the wrongdoer confirms that the allegations are true, and thereby loses the benefit of the doubt (6). Moreover, an admission might be used in evidence, for example in a court case. But wrongdoers also neglect to admit fault because it is unpleasant to do so. Okimoto and colleagues (9) found that participants who were asked apologize for a past transgression felt worse about themselves than participants who were asked to refuse to do so. In sum, wrongdoers often neglect to admit fault when apologizing - but by doing so, impede the victim's restoration, as well as their own chances of being forgiven.

When responding to true accusations, wrongdoers therefore should (at least) admit fault, and express remorse for their actions $(6,7)$. In addition, it is desirable that they acknowledge the victim's harm, and to offer to restore it (8). But does that mean that an apology that contains these elements will be effective? To answer this question, it is interesting to consider Louis CK's statement, in response to accusations by several female actors and comedians.

\footnotetext{
"These stories are true. At the time, I said to myself that what I did was O.K. because I never showed a woman my dick without asking first (...) But what I learned later in life, too late, is that when you have power over another person, asking them to look at your dick (...) [is] a predicament (...) I have been remorseful of my actions (...).

I learned yesterday the extent to which I left these women who admired me feeling badly about themselves and cautious around other men (...). I also took advantage of the fact that I was widely admired in my and their community, which disabled them from sharing their story (...). There is nothing about this that I forgive myself for (...).

The hardest regret to live with is what you've done to hurt someone else. And I can hardly wrap my head around the scope of hurt I brought on them. (...) I have spent my long and lucky career talking and saying anything I want. I will now step back and take a long time to listen." (Louis CK)
} 
At first glance, this response seems to contain all the necessary elements. CK admits that "[the] stories are true." He recognizes how his position of power robbed his victims of choice and silenced them. By doing so, he seems to clearly admit fault. Furthermore, he states that he is "remorseful of [his] actions", and implies a willingness to make amends and not reoffend ("I will now step back and take a long time to listen"). This way, CK's apology features critical elements that Spacey's response is lacking.

Does that mean that his apology will be effective? This is still questionable. Like Spacey, CK hints at excuses and mitigating circumstances. For example, he implies that he was not aware of misbehaving ("I [only] learned later in life," "I learned [only] yesterday"), and does not neglect to mention that victims consented, despite their limited choice ("I never [did]... without asking first"). In addition, much of the statement is about himself, such as how unpleasant the affair has been for him ("the hardest regret to live with..."), or how much he was admired (no less than four times, in the full statement). Defensive, mitigating elements such as these are likely to undermine an apology, even when the wrongdoer clearly admits fault (8).

\section{Sincere apologies and the (rocky) road to redemption}

How then should suspects respond to \#MeToo-allegations? In the case that they are innocent, it seems that the best strategy is to deny everything (4). Apologizing partially (like Spacey) is likely to backfire: if they seem to be apologizing for something, others are likely to assume that they must also be responsible. Indeed, in the job interview experiment (4), participants had less trust in the candidate if he/she apologized, even if his/her innocence was subsequently proven. 
If the suspect is truly responsible, the easiest route is to deny. By doing so, the wrongdoer may retain the benefit of the doubt with the general public, while avoiding the cost of confession. However, denial does not help the victim recover, nor does it enable the wrongdoer to be forgiven. Moreover, denying is not without risk: new evidence will expose the wrongdoer as not only guilty, but also a liar. In this case, the road to forgiveness and redemption will be even more difficult (4).

The more difficult route for wrongdoers is to apologize. In this case, it is necessary that they admit fault, plainly and without excuses. Moreover, they must express sincere remorse (6, 7). In the short run, doing so will be painful and humiliating. They will lose the benefit of the doubt, and will have to suffer the consequences: socially, financially, and perhaps legally. In the long run, however, remorse and atonement is a critical first step in the forgiveness process ( 7 , 10). By apologizing, they respond to the victim's need for acknowledgement, and the public's desire for affirmation of the norms and values that they have broken (11). Their submission may also evoke empathy, which may reduce the desire to punish or exclude them (3). Ultimately, this process may lead to forgiveness, and readmission to the community.

In this process, it is crucial that wrongdoers do not simply leave it at words. Firstly, they should visibly show better conduct, and refrain from further transgressions (as opposed to Louis CK, who has continued to joke about sexual misconduct). Moreover, apologies become more meaningful when followed by concrete steps to restore the harm, as a study by Bottom and colleagues illustrates (12). Participants who suffered a loss due to another participant were more inclined to cooperate when the wrongdoer did not only apologize, but also restored their losses. Wrongdoers should also take concrete steps to restore the victim and undo their wrongs. In the case of \#MeToo, it is possible that victims will regard it as inappropriate to be "paid" after sexual 
misconduct. In this context, a donation to a relevant noble cause (for example to a victim relief organization) may be a better response.

Can perpetrators of \#MeToo-abuse be forgiven and return to society? At present, the answer to these questions is still unclear. \#MeToo-accusations deal with severe misconduct that is claimed to have happened repeatedly, across a range of victims. Whether such behavior can be forgiven is uncertain. Indeed, research suggests that some crimes may never be forgiven (13). The future will show if \#MeToo-suspects can receive forgiveness and redemption. It seems unlikely that the responses of Weinstein, Spacey and CK will do much to promote this, however.

\section{Glossary}

\#MeToo

Movement in which (alleged) victims of sexual misconduct challenge the (alleged) perpetrator publically via social media

Denial Statement whereby an allegation is explicitly declared to be untrue (Kim et al., 2004)

Excuse Response that places blame outside of the accused or mitigates his/her responsibility

Forgiveness

The extent to which one has let go (mostly or completely) of negative feelings, thoughts and behaviors toward the perpetrator

Apology

Statement in which the perpetrator admits fault for an offense and offers remorse for it (Lazare, 2004; Tavuchis, 1991)

Trust

State in which one is willing to accept vulnerability based on positive expectations of another (Rousseau et al., 1998) 


\section{References}

1. Kim, P.H., Dirks, K.T., \& Cooper, C.D. (2009). The repair of trust: a dynamic bilateral perspective and multilevel conceptualization. Academy of Management Review, 34, 401422.

2. Rousseau, D.M., Sitkin, S.B., Burt, R.S., \& Camerer, C. (1998). Not so different after all: A cross-discipline view of trust. Academy of Management Review, 23, 393-404.

3. McCullough, M.E. (2001). Forgiveness: who does it and how do they do it? Current Directions in Psychological Science, 10, 194-197.

4. Kim, P.H., Ferrin, D.L., Cooper, C.D., \& Dirks, K.T. (2004). Removing the shadow of suspicion: the effects of apology versus denial for repairing competence- versus integritybased trust violations. Journal of Applied Psychology, 89, 104-118.

5. Bowles, S., \& Gintis, H. (2004). Persistent parochialism: trust and exclusion in ethnic networks. Journal of Economic Behavior \& Organization, 55, 1-23.

6. Lazare, A. (2004). On apology. New York: Oxford University Press.

7. Tavuchis, N. (1991). Mea Culpa: A sociology of apology and reconciliation. Stanford: Stanford University Press.

8. Schumann, K. (2014). An affirmed self and a better apology: The effect of selfaffirmation on transgressors' responses to victims. Journal of Experimental Social Psychology, 54, 89-96.

9. Okimoto, T.G., Wenzel, M., \& Hedrick, K. (2013). Refusing to apologize can have psychological benefits (and we issue no mea culpa for this research finding). European Journal of Social Psychology, 43, 22-31. 
10. Shnabel, N., \& Nadler, A. (2015). The role of agency and morality in reconciliation processes: the perspective of the needs-based model. Current Directions in Psychological Science, 24, 477-483.

11. Wenzel, M., Okimoto, T.G., Feather, N.T., \& Platow, M.J. (2008). Retributive and restorative justice. Law and Human Behavior, 32, 375-389.

12. Bottom, W.P., Gibson, K., Daniels, S.E., \& Murnighan, J.K. (2002). When talk is not cheap: substantive penance and expressions of intent in rebuilding cooperation. Organization Science, 13, 497-513.

13. Cohen, A.B., Malka, A., Rozin, P., \& Cherfas, L. (2006). Religion and unforgivable offenses. Journal of Personality, 74, 85-118. 